\title{
Serum vitamin A and E, copper, zinc and selenium concentrations and their relationship with health outcomes in dromedary hospitalized camels (Camelus dromedarius)
}

\author{
Hany Hassan ${ }^{1, *}$, Ahmed Zaghawa ${ }^{2}$, Ahmed Kamr ${ }^{1}$, Mahmoud Aly ${ }^{1}$, Mohamed Nayel ${ }^{2}$, Ahmed Elsify ${ }^{2}$, \\ Akram Salama $^{2}$ and Ali Abdelazeim ${ }^{1}$ \\ ${ }^{1}$ Department of Animal Medicine and Infectious Diseases (Animal Internal Medicine), Faculty of Veterinary \\ Medicine, University of Sadat City, Sadat City 32897, Egypt \\ ${ }^{2}$ Department of Animal Medicine and Infectious Diseases (Infectious Diseases), Faculty of Veterinary Medicine, \\ University of Sadat City, Sadat City 32897, Egypt
}

\begin{abstract}
The goals of this study were to measure serum vitamin A (retinol) and E ( $\alpha$-tocopherol) and trace elements concentrations (copper, zinc and selenium) during diseases condition and to determine their association with hematological parameters and immune status of hospitalized camels. A total of 95 dromedary camels [healthy ( $\mathrm{n}=65$ ); hospitalized camels $(n=30)]$ were included in this study. Vitamin A and E concentrations were significantly lower in hospitalized camels than apparently healthy ones $(\mathrm{P}<0.05)$. Hospitalized camels had lower concentrations of zinc and selenium compared to healthy camels $(\mathrm{P}<0.05)$. Vitamin $\mathrm{E}$, copper, zinc and selenium concentrations were positively correlated with phagocytic activity in hospitalized camels $(\mathrm{P}<0.05)$. The likelihood of deficiency of vitamin $\mathrm{A}$ and $\mathrm{E}$, zinc and selenium concentrations were significant in female hospitalized camels than males and in young age hospitalized camels $<6$ years old compared to old ones $(\mathrm{P}<0.05)$. Decreased vitamin A and $\mathrm{E}$ and trace elements concentrations were associated with hospitalized camels' phagocytic activity and index. The prevalence of low vitamin $\mathrm{A}$ and $\mathrm{E}$, zinc and selenium concentrations were frequent in female hospitalized camels and hospitalized camels of age $<6$ years old suggesting severe oxidative stress.
\end{abstract}

Keywords: Camel, Copper, Selenium, Vitamin, Zinc.

\begin{abstract}
Introduction
Vitamins and trace elements are needed in small amount for vital functions in many animal species including energy production, enzyme activity, resistance against diseases and their deficiencies result in immunological dysfunction and other metabolic disorders (Underwood and Arthur, 1996). Low vitamin $\mathrm{A}$ and $\mathrm{E}$, copper, zinc and selenium concentrations lead to many problems eg. decreased reproduction and oxidative stress in farm animals including camels; however, their association with the immune status of camels requires further investigation.

Vitamin A plays essential role in epithelization of many organs and immunomodulation against infection. Additionally, it has been reported that vitamin A is deficient in feeding regimen of the farm animals therefore, its dietary supplementation is very necessary to the ruminant diet (Duester, 2008; Baraka, 2012; Pourjafar et al., 2014).

Vitamin $\mathrm{E}$ is also involved in many physiological processes against free radicals and poly unsaturated fatty acids that in turn prevent muscular and cellular injury and oxidative stress (Bennett and Brown, 2003; Baraka, 2012).
\end{abstract}

Trace elements including copper, zinc and selenium had an important antioxidants function; they also play a role in maintaining normal oxidants/antioxidants and immunomodulation (Hambidge, 2003; Nayyar and Jindal, 2010; Pourjafar et al., 2014).

Of interest, vitamins and trace elements is a contributory factor in the process of phagocytosis that categorized into chemotaxis (migration of phagocytes to inflammatory sites), attachment of particles to the cell surface of phagocytes, ingestion (phagocytosis) and intracellular killing by oxygen-dependent (oxidative burst) and oxygen independent mechanisms (Roitt et al., 1996; Bhaskaram, 2002; Mehrzad et al., 2014). This raises a question whether vitamin $A$ and $E$ and trace elements status will have impact on phagocytic index and phagocytic activity in hospitalized camels. Moreover, serum concentrations of vitamin A, E and micro-elements based on sex and age require further investigation in poor conditioned hospitalized camels during admission time.

The aims of this study were to determine vitamin A, E, copper, zinc and selenium status during diseased conditions of dromedary hospitalized camels and to determine their association with their immune status 
and health outcomes. We hypothesized that vitamin A, $\mathrm{E}$, copper, zinc and selenium concentrations will be frequent finding during time of hospitalization and associated with their health outcomes.

\section{Animals' criteria}

\section{Materials and Methods}

A total of 95 adult camels (Camelus dromedarius), of different age and sex were involved in this study. The camels were divided into two main groups. Group1: Included 65 apparently healthy camels and their health status were confirmed by physical examination in the farm and their body condition score $(\mathrm{BCS}=3-5)$ by inspection and manual palpation (Crabb et al., 1990; Faye et al., 2001). Group 2: Included 30 hospitalized camels admitted to veterinary clinics at different area at Menofia Governorate suffered from many pathological conditions including Gastrointestinal affections $(n=8)$, rough hair coat $(6)$, lacrimation $(n=5)$, coughing with nasal discharge $(n=7)$, and ticks with pale mucus membrane $(n=4)$ and were confirmed by physical examination and their $\mathrm{BCS}=1-2$ due to pathological conditions during time of hospitalization (Crabb et al., 1990; Faye et al., 2001).

Hospitalized camels (Group 2) were further divided into subgroups based on vitamins and trace elements concentrations. Subgroup 2.1: included 10 dromedary camels with lower blood serum values of copper and selenium ( $\downarrow \mathrm{Cu}, \mathrm{Se})$. Subgroup 2.2: included 4 camels with lower blood serum values of copper and vitamin A ( $\downarrow$ Cu, vitamin A). Subgroup 2.3: Included 7 camels with lower blood serum values of copper, zinc and vitamin $\mathrm{E}$ ( $\downarrow \mathrm{Cu}, \mathrm{Zn}$, vitamin E). Subgroup 2.4: Included 4 camels with lower blood serum values of vitamin $\mathrm{E}$ and zinc ( $\downarrow$ vitamin E, Zn). Subgroup 2.5: Included 5 camels with lower blood serum values of vitamin $A$ and selenium ( $\downarrow$ vitamin A, Se).

Hospitalized camels $(n=30)$ were further divided based on their sex into females $(n=13)$ and males $(n=17)$. Hospitalized camels were admitted to veterinary clinics with different age ranged from 4 to 12 years old and were classified based on mean of age in to hospitalized camels $<6$ and $>6$ years old.

\section{Clinical information}

Camels' clinical history obtained from their owners. Physical examination, serum biochemistry and hemogram were determined for each camel. Body condition scoring in camels was done based on a visual and tactile evaluation of body fat reserves. BCS was evaluated by assigning a rating scale that ranges from 1 (indistinct hump on the dorsal length of the body, the ribs were markedly visible, the ischial and coxal tuberosities, transverse processes of vertebrae were very prominent and the rectogenital zone was very deep ) to 5 (The hump base occupies more than $70 \%$ of the dorsal length of the body, the ribs were not visible, the ischial and coxal tuberosities, transverse processes of vertebrae were not visible and not felt and the rectogenital zone was fully fat) (Crabb et al., 1990; Faye et al, 2001).

\section{Sampling}

Three blood samples were collected from jugular vein of each camel using sterile syringe. The first one was collected in dry clean labeled test tube contain anticoagulant, Ethylene diamine tetra acetic acid (EDTA) for complete blood count (CBC) and the second one contains heparin for determination of phagocytic index. While the third one collected in dry clean centrifuge tube and kept in sloping position without agitation till coagulation. The clotted samples were centrifuged at $3000 \mathrm{rpm}$ for 10 minutes for separation of a clear non-hemolysed serum for biochemical analysis. Sera were kept in deep freezer at -20 till biochemical analysis.

\section{Hematological and biochemical measurements}

Hematological examinations were carried according to method described by Schalm et al. (1975); Coles (1986) and Tietz (1999). Vitamin A (retinol) concentrations were measured chemically ( $1 \mathrm{ml}$ of each serum sample was mixed with $1.0 \mathrm{ml}$ of $96.5 \%$ ethanol in a test tube,

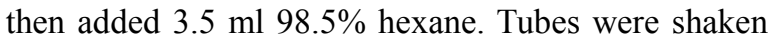
for 10 minutes and centrifuged at $800-\times \mathrm{g}$ for 10 minutes. The supernatants were measured at double waves length include $453 \mathrm{~nm}$ and $325 \mathrm{~nm}$ then final concentrations calculated by equations according to method described by Suzuki and Katoh (1990). Vitamin E ( $\alpha$-tocopherol) concentrations were assessed spectrophotometrically at different wave lengths with mathematical equations (Robert, 1964). Copper and zinc were measured in serum by UV- colorimetric spectrophotometric method (110-220 V UNICO Ltd, USA), using special copper and zinc kit produced by (Spectrum company, Egypt) according to method described by Johnsen and Eliasson (1987) and Abe et al. (1989). Selenium was measured in serum using acetylene air atomic absorption spectrophotometer (Tsoumbaris, 1990). Total protein and albumin were measured in serum by UV- colorimetric spectrophotometric method using total protein kit that was produced by Vitro Scient Company (Young, 2001). Globulin was calculated by subtraction of albumin value from total protein value and then $\mathrm{A} / \mathrm{G}$ ratio was calculated by dividing albumin concentration on globulin concentration (Doumas, 1975).

\section{Phagocytic activity and phagocytic index determination}

Phagocytosis of polymorphnuclear cells using Candida albicans was performed according to the following method described by Wilkinson (1981).

Phagocytic activity \% (PA) = Number of neutrophils ingesting Candida albicans / 100 neutrophil cells.

Phagocytic index $(\mathrm{PI})=$ Total number of phagocytosed Candida albicans / Phagocytic activity. 


\section{Statistical analysis}

Data were assed for normality and they were normally distributed by Shapiro Wilk test. Statistical analysis was performed using the statistical package for social science (SPSS) for windows (Version 16.0; SPSS INC., Chicago,Ill.). Fisher's exact test was carried out to determine the proportions of vitamin A, E, copper, zinc and selenium concentrations in hospitalized camels. $\mathrm{T}$ test was used to compare between the two groups of camels, while MANOVA test was used to determine significant differences among subgroups of hospitalized camels with Duncan as a post hoc. Pearson's correlations were used to determine significance between phagocytic index and low concentrations of vitamin A, E, copper, zinc and selenium in hospitalized camels. Results were expressed as the mean \pm standard error (SEM). Odds ratios with $95 \%$ confidence interval (CI) were carried out to determine the effect of sex and age on the prevalence of the measured variables. Significance was set at $\mathrm{P}<0.05$. Cut-off values of vitamin $\mathrm{A}, \mathrm{E}$, zinc, selenium and copper concentrations were defined based on $5-95 \%$ CI of mean from apparently healthy camels where concentrations $<5 \%$ CI were considered low, while above $95 \%$ CI were defined as high concentrations.

\section{Results}

Prevalence of serum vitamin $A, E$ and copper, zinc and selenium concentrations in hospitalized camels

In hospitalized camels, the prevalence of reduced vitamin A concentrations were more frequent than normal and elevated vitamin A concentrations in female hospitalized camels and age $<6$ years old $(\mathrm{P}<0.05$; Table1). Reduced vitamin E concentrations were more prevailed than normal and increased vitamin $\mathrm{E}$ concentrations in hospitalized female camels and camels with age $<6$ and $>6$ years old $(\mathrm{P}<0.05$; Table $1)$. Normocupraemia was more prevailed than reduced and elevated copper concentrations in hospitalized female and male camels, however, in hospitalized camels with age $<6$ years, reduced and normal copper concentrations was more frequent than elevated copper concentrations $\quad(\mathrm{P}<0.05 ;$ Table 1). Low zinc concentrations were more frequent in female hospitalized camels and camels with age $<6$ and $>6$ years than normal and higher zinc concentrations $(\mathrm{P}<0.05$; Table 1$)$. Low selenium concentrations were more frequent in females and males hospitalized camels than normal and high selenium concentrations $(\mathrm{P}<0.05$; Table 1).

Serum vitamin $A$ and $E$, copper, zinc and selenium in healthy and hospitalized camels

Hospitalized female camels had lower serum concentrations of vitamin A and E, zinc and selenium compared to healthy and hospitalized male camels $(\mathrm{P}<0.05$; Table 2). Hospitalized male camels had low concentrations of vitamin $\mathrm{E}$, selenium and zinc compared to healthy ones $(\mathrm{P}<0.05$; Table 2). Hospitalized camels with age $<6$ years old had lower serum concentrations of vitamin $\mathrm{A}$ and $\mathrm{E}$, zinc and selenium compared to healthy and hospitalized camels of age $>6$ years old $(\mathrm{P}<0.05$; Table 2$)$. However, serum copper were not changed between healthy and hospitalized camels $(\mathrm{P}>0.05)$ (Table 2$)$. Serum vitamin $\mathrm{A}$ and $\mathrm{E}$, zinc and selenium concentrations were lower in poor conditioned hospitalized camels compared to healthy ones $(\mathrm{P}<0.05$; Table 3$)$.

Hematological examination in healthy and hospitalized camels

The mean values of the RBCs, $\mathrm{Hb}$ and PCV were significantly lower in hospitalized camels compared to apparently healthy ones $(\mathrm{P}<0.05)$. Furthermore, RBCs, $\mathrm{Hb}$ and $\mathrm{PCV}$ were significantly lowered in subgroup 1 and subgroup 3 compared to other subgroups and apparently healthy ones $(\mathrm{P}<0.05)$. MCV values were significantly higher in subgroups $1,2,3$, and subgroup 5 compared to apparently healthy camels $(\mathrm{P}<0.05)$, while no changes in values of $\mathrm{MCH}$ and $\mathrm{MCHC}$ between two main groups except subgroup 4 where MCHC value was significantly higher than control group as shown in Table 4. Table 4 illustrated that WBCS were significantly lower in hospitalized dromedary camels compared to apparently healthy ones $(\mathrm{P}<0.05)$. Moreover, WBCS were significantly decreased in subgroups 1, 2 and subgroup 3 compared to other subgroups and healthy control ones $(\mathrm{P}<0.05)$. The mean values of neutrophils were significantly lower in 5 subgroups compared healthy ones $(\mathrm{P}<0.05)$. Lymphocytes were significantly lower in subgroup 1 and subgroup 3, but higher in subgroups 2, 4 and 5 compared to apparently healthy camels $(\mathrm{P}<0.05)$. Eosinophils' count were statistically higher in subgroup 1 and subgroup 3 compared to other subgroups and healthy ones $(\mathrm{P}<0.05)$. There is no changes in monocytes and basophiles between the two main groups and other subgroups $(\mathrm{P}>0.05)$.

Total protein, Albumin, Globulin, and $A / G$ ratio in healthy and hospitalized camels

Total protein and albumin concentrations were significantly lower in hospitalized dromedary camels compared to apparently healthy ones $(\mathrm{P}<0.05)$. There is no significant changes in the mean values of globulin and $\mathrm{A} / \mathrm{G}$ ratio between two main groups $(\mathrm{P}>0.05)$ as demonstrated in Table 4.

Correlation between trace elements, vitamins and phagocytic index

Vitamin A concentrations were not correlated with phagocytic index in diseased dromedary camels, while there were a positively correlation between low concentration of serum copper, Selenium, and vitamin $\mathrm{E}$ and phagocytic index in diseased dromedary camels as documented in Table 5. 
Table 1. Prevalence of serum vitamin A, E and copper, zinc and selenium concentrations in hospitalized camels.

\begin{tabular}{lcccc}
\hline \multirow{2}{*}{ Prevalence } & \multicolumn{4}{c}{ Hospitalized $(\mathrm{n}=30)$} \\
\cline { 2 - 5 } & Females $(\mathrm{n}=13)$ & Males $(\mathrm{n}=17)$ & $<6$ years $(\mathrm{n}=19)$ & $>6$ years $(\mathrm{n}=11)$ \\
\hline Low vitamin A concentrations & $61.5 \%(8 / 13)^{* *}$ & $58.9 \%(10 / 17)$ & $68.4 \%(13 / 19)^{* *}$ & $54.5 \%(6 / 11)$ \\
Normal vitamin A concentration & $38.5 \%(5 / 13)$ & $41.1(7 / 17)$ & $31.6 \%(6 / 19)$ & $45.6 \%(5 / 11)$ \\
Elevated vitamin A concentration & 0 & 0 & 0 & 0 \\
Low vitamin E concentrations & $69.2 \%(9 / 13)^{*}$ & $52.9 \%(9 / 17)$ & $73.6 \%(14 / 19)^{* *}$ & $63.6 \%(7 / 11)^{* *}$ \\
Normal vitamin E concentration & $30.8(4 / 13)$ & $47.1 \%(8 / 17)$ & $26.4 \%(5 / 19)$ & $36.4 \%(4 / 11)$ \\
Elevated vitamin E concentration & 0 & 0 & 0 & 0 \\
Low copper concentrations & $23.1 \%(3 / 13)$ & $41.2 \%(7 / 17)$ & $42.1(8 / 19)^{* *}$ & $36.3(4 / 11)^{* *}$ \\
Normal copper concentration & $53.8 \%(7 / 13)^{* *}$ & $52.9 \%(9 / 17)^{* *}$ & $42.1 \%(8 / 19)^{* *}$ & $54.6(6 / 11)^{* *}$ \\
\hline Elevated copper concentration & $23.1 \%(3 / 13)$ & $5.9 \%(1 / 17)$ & $15.8 \%(3 / 19)$ & $9.1 \%(1 / 11)$ \\
Low zinc concentrations & $61.5 \%(8 / 13)^{*}$ & $47.1(8 / 17)$ & $63.2 \%(12 / 19)^{* *}$ & $72.7 \%(8 / 11)^{* *}$ \\
Normal Zinc concentrations & $38.3(5 / 13)$ & $52.9(9 / 17)$ & $36.8 \%(7 / 19)$ & $27.3 \%(3 / 11)$ \\
High Zinc concentrations & 0 & 0 & 0 & 0 \\
Low selenium concentrations & $61.5 \%(8 / 13)^{* *}$ & $76.5 \%(13 / 17)^{* *}$ & $63.2 \%(12 / 19)$ & $45.5 \%(5 / 11)$ \\
Normal selenium concentrations & $38.5 \%(5 / 13)$ & $23.5 \%(4 / 17)$ & $36.8 \%(7 / 19)$ & $54.5 \%(6 / 11)$ \\
\hline High selenium concentrations & 0 & 0 & 0 & 0 \\
\hline
\end{tabular}

(n): number; $(*): \mathrm{P}<0.05 ;(* *): \mathrm{P}<0.01$.

Table 2. Serum Vitamin A and Vitamin E values in apparently healthy and hospitalized dromedary camels

\begin{tabular}{lccccc}
\hline \multirow{2}{*}{ Variables } & Healthy & \multicolumn{4}{c}{ Hospitalized camels $(30)$} \\
\cline { 2 - 6 } & Camels $(\mathrm{n}=65)$ & Females $(\mathrm{n}=13)$ & Males $(\mathrm{n}=17)$ & $<6$ years $(\mathrm{n}=19)$ & $>6$ years $(\mathrm{n}=11)$ \\
\hline Vitamin $\mathrm{A}(\mu \mathrm{g} / \mathrm{dl})$ & $69.1 \pm 2.3$ & $60.5 \pm 1.2^{*}$ & $64.3 \pm 3.2$ & $61.4 \pm 2.4^{*}$ & $64.6 \pm 0.9$ \\
Vitamin E $(\mathrm{mg} / 100 \mathrm{ml})$ & $1.06 \pm 0.2$ & $0.74 \pm 0.4^{* *}$ & $0.84 \pm 0.1^{*}$ & $0.86 \pm 0.2^{*}$ & $0.93 \pm 0.1$ \\
Copper $(\mu \mathrm{g} / \mathrm{dl})$ & $92.7 \pm 2.5$ & $92.97 \pm 1.8$ & $92.34 \pm 3.2$ & $92.57 \pm 4.1$ & $92.47 \pm 3.2$ \\
Selenium $(\mathrm{ppm})$ & $0.5 \pm 0.3$ & $0.30 \pm 0.1^{*}$ & $0.36 \pm 0.2^{*}$ & $0.34 \pm 0.3^{*}$ & $0.45 \pm 0.2$ \\
Zinc $(\mu \mathrm{g} / \mathrm{dl})$ & $121.2 \pm 4.6$ & $104.2 \pm 5.2^{*}$ & $116.2 \pm 3.5$ & $107.6 \pm 1.4^{*}$ & $114.8 \pm 2.5$ \\
\hline
\end{tabular}

(n): number; $(*): \mathrm{P}<0.05 ;(* *): \mathrm{P}<0.01$.

Table 3. Serum Vitamin A, Vitamin E and copper, selenium and zinc values in apparently healthy and hospitalized camels.

\begin{tabular}{lcc}
\hline Variables & $\begin{array}{c}\text { Healthy } \\
\text { camels }\end{array}$ & $\begin{array}{c}\text { Hospitalized } \\
\text { camels }\end{array}$ \\
\hline Vitamin A $(\mu \mathrm{g} / \mathrm{dl})$ & $69.1 \pm 2.3$ & $59.2 \pm 0.4^{*}$ \\
Vitamin $\mathrm{E}(\mathrm{mg} / 100 \mathrm{ml})$ & $1.06 \pm 0.2$ & $0.76 \pm 0.033^{*}$ \\
Copper $(\mu \mathrm{g} / \mathrm{dl})$ & $92.7 \pm 2.5$ & $92.97 \pm 0.471$ \\
Selenium $(\mathrm{ppm})$ & $0.5 \pm 0.3$ & $0.295 \pm 0.013^{* *}$ \\
Zinc $(\mu \mathrm{g} / \mathrm{dl})$ & $121.2 \pm 4.6$ & $104.2 \pm 2.4^{*}$ \\
\hline
\end{tabular}

$(*): \mathrm{P}<0.05 ;(* *): \mathrm{P}<0.01$.

\section{Phagocytic activity and phagocytic index in healthy} and hospitalized camels

The phagocytic activity and phagocytic index were significantly lower in hospitalized one dromedary camels compared to apparently healthy ones $(\mathrm{P}<0.05)$. The mean values of phagocytic activity were significantly lower in subgroups 3, 4 and subgroup 5 compared to other subgroups, while the mean values of phagocytic index were significantly decreased in subgroups 1, 3, and subgroup 5 as shown in Fig 1. Engulfed Candida albicans were presented in large numbers by active neutrophils in good conditioned healthy camels (Fig 2 A). Blood film showed that large numbers of inactive neutrophils in hospitalized camels with low concentrations of vitamin $\mathrm{A}$ and $\mathrm{E}$ and trace elements (Fig 2B).

Serum vitamin $A$ and $E$, copper, zinc and selenium concentrations in hospitalized camels based on sex and age

Female hospitalized camels were more likely to have low vitamin A concentrations compared to male hospitalized camels (Table 6). Hospitalized camels with age $<6$ years old were more likely to have low vitamin A concentrations compared with hospitalized camels with age $>6$ years old (Table 6). The likelihood of vitamin E deficiency was more significant in female hospitalized camels and younger age hospitalized camels $<6$ years old $(\mathrm{P}<0.05$; Table 6$)$. The likelihood of copper concentrations were not significant between sex and age of hospitalized camels ( $P>0.05$; Table 6$)$. Female hospitalized camels were more likely to have low zinc and selenium concentrations compared with male hospitalized camels (Table 6). 
Table 4. Hematological and biochemical analysis in apparently healthy camels, hospitalized dromedary camels and subgroups. Values were expressed as $(\mathrm{MV} \pm \mathrm{SE})$.

\begin{tabular}{|c|c|c|c|c|c|c|}
\hline \multirow[b]{2}{*}{ Variables } & \multirow[b]{2}{*}{$\begin{array}{c}\text { Apparently } \\
\text { healthy camels } \\
\quad(n=65)\end{array}$} & \multicolumn{5}{|c|}{ Hospitalized camels $(n=30)$} \\
\hline & & $\begin{array}{l}\text { Subgroup } 2.1 \\
(\downarrow \mathrm{Cu}, \mathrm{Se}) \\
(\mathrm{n}=10)\end{array}$ & $\begin{array}{l}\text { Subgroup2.2 } \\
(\downarrow \mathrm{Cu}, \mathrm{Vit} A) \\
(\mathrm{n}=4)\end{array}$ & $\begin{array}{c}\text { Subgroup2.3 } \\
(\downarrow \mathrm{Cu}, \mathrm{Zn}, \text { Vit E) } \\
(\mathrm{n}=7)\end{array}$ & $\begin{array}{c}\text { Subgroup } 2.4 \\
(\downarrow \text { Vit } E, Z n) \\
(n=4)\end{array}$ & $\begin{array}{c}\text { Subgroup } 2.5 \\
(\downarrow \text { Vit A, Se) } \\
(n=5)\end{array}$ \\
\hline RBCs $(106 / \mu 1)$ & $7.358 \pm 0.1071$ & $5.56 \pm 0.04^{* *, a}$ & $6.15 \pm 0.15^{*}$ & $5.91 \pm 0.15^{* *, \mathrm{~b}}$ & $6.87 \pm 0.11 *$ & $6.18 \pm 0.28 *$ \\
\hline $\mathrm{Hb}(\mathrm{g} / \mathrm{dl})$ & $12.99 \pm 0.0859$ & $10.2 \pm 0.05^{* *, \mathrm{a}}$ & $11.2 \pm 0.14^{*, \mathrm{~b}}$ & $11.1 \pm 0.38 * * \mathrm{c}$ & $12.8 \pm 0.14$ & $11.6 \pm 0.26^{*}$ \\
\hline $\operatorname{PCV}(\%)$ & $29.33 \pm 0.3281$ & $23.6 \pm 0.4 * *, \mathrm{a}$ & $25.2 \pm 0.25 * *, \mathrm{~b}$ & $25.5 \pm 0.86 * *, \mathrm{c}$ & $27.75 \pm 0.25 *$ & $26.2 \pm 0.31 *$ \\
\hline MCV (fi) & $40.64 \pm 0.8006$ & $42.4 \pm 0.4 *$ & $41.2 \pm 1.02 *$ & $43.05 \pm 0.9 *$ & $40.3 \pm 0.9$ & $42 \pm 1.4 *$ \\
\hline $\mathrm{MCH}(\mathrm{pg})$ & $17.79 \pm 0.3215$ & $18.4 \pm 0.13$ & $18.25 \pm 0.39$ & $18.6 \pm 0.3$ & $18.65 \pm 0.4$ & $19.2 \pm 0.4$ \\
\hline $\mathrm{MCHC}(\%)$ & $44.57 \pm 0.5103$ & $43.4 \pm 0.7$ & $43.2 \pm 1.03$ & $43.1 \pm 0.9$ & $46.08 \pm 0.4 *$ & $44.56 \pm 0.6$ \\
\hline WBCs $\left(10^{3} / \mu \mathrm{l}\right)$ & $13.84 \pm 0.156$ & $10.7 \pm 0.1 * *, \mathrm{a}$ & $11.6 \pm 0.08 * *, \mathrm{~b}$ & $11.5 \pm 0.3^{* *, \mathrm{c}}$ & $12.35 \pm 0.22 *$ & $11.96 \pm 0.23 *$ \\
\hline Neutrophil (\%) & $42.44 \pm 0.143$ & $41.3 \pm 0.21 *$ & $41.75 \pm 0.25 *$ & $41.29 \pm 0.18 *$ & $41.25 \pm 0.47 *$ & $41.2 \pm 0.48^{*}$ \\
\hline Lymphocyte (\%) & $51.00 \pm 0.190$ & $50.2 \pm 0.13 *$ & $51.75 \pm 0.25$ & $50.14 \pm 0.14 *$ & $52.25 \pm 0.25$ & $52.4 \pm 0.244$ \\
\hline Monocyte (\%) & $4.750 \pm 0.090$ & $5.3 \pm 0.152$ & $5 \pm 0.00$ & $5.14 \pm 0.14$ & $5 \pm 0.00$ & $5 \pm 0.00$ \\
\hline Esinophil (\%) & $1.327 \pm 0.085$ & $2.6 \pm 0.16^{*}$ & $1 \pm 0.00$ & $2.57 \pm 0.297 *$ & $1.25 \pm 0.25$ & $1.2 \pm 0.2$ \\
\hline Basophil (\%) & $0.5000 \pm 0.80$ & $0.8 \pm 0.13$ & $0.5 \pm 0.288$ & $0.85 \pm 0.14$ & $0.75 \pm 0.25$ & $0.2 \pm 0.2$ \\
\hline $\begin{array}{l}\text { Total protein } \\
(\mathrm{gm} / \mathrm{dl})\end{array}$ & $6.831 \pm 0.03558$ & $6.06 \pm 0.065 *$ & $5.8 \pm 0.067 *$ & $6.025 \pm 0.08 *$ & $5.98 \pm 0.25 *$ & $5.99 \pm 0.11 *$ \\
\hline Albumin (gm/dl) & $3.697 \pm 0.03962$ & $3.014 \pm 0.04 *$ & $2.98 \pm 0.08 *$ & $2.95 \pm 0.04 *$ & $3.04 \pm 0.069 *$ & $3.12 \pm 0.107 *$ \\
\hline Globulin (gm/dl) & $3.148 \pm 0.05249$ & $3.046 \pm 0.06$ & $3.03 \pm 0.08$ & $3.07 \pm 0.066$ & $3.04 \pm 0.069$ & $3.12 \pm 0.107$ \\
\hline $\mathrm{A} / \mathrm{G}$ ratios & $1.187 \pm 0.02844$ & $0.958 \pm 0.032 *$ & $0.97 \pm 0.6$ & $0.93 \pm 0.04 *$ & $1.02 \pm 0.04$ & $0.96 \pm 0.057$ \\
\hline
\end{tabular}

(RBCs): red blood cells; (Hb): hemoglobin; (PCV): packed cell volume; (MCV): mean corpuscular volume; (MCH): mean corpuscular hemoglobin; (MCHC): mean corpuscular hemoglobin concentrations; (WBCs): white blood cells; (A/G): Albumin/Globulin, (Cu): copper; (Se): selenium; (Zn): zinc; (Vit A): vitamin A; (Vit E): vitamin E. $\left({ }^{*}\right)$ : $\mathrm{P}<0.05 ;(* *)$ : $\mathrm{P}<0.01$. Subgroups with different letters $\left({ }^{\mathrm{a}, \mathrm{b}, \mathrm{c}}\right.$ ) indicate statistical significantly difference than other subgroups $(\mathrm{P}<0.05)$.

Table 5. Pearson correlation $(r)$ between low concentration of copper, zinc, selenium, vitamin $\mathrm{A}$, vitamin $\mathrm{E}$ and phagocytic index in diseased dromedary camels.

\begin{tabular}{lcc}
\hline Variables & Phagocytic index $(r)$ & P-value \\
\hline Copper & 0.5 & $0.03^{* *}$ \\
Zinc & 0.07 & 0.7 \\
Selenium & 0.490 & $0.02 *$ \\
Vitamin A & 0.03 & 0.6 \\
Vitamin E & 0.5 & $0.02 * *$ \\
\hline
\end{tabular}

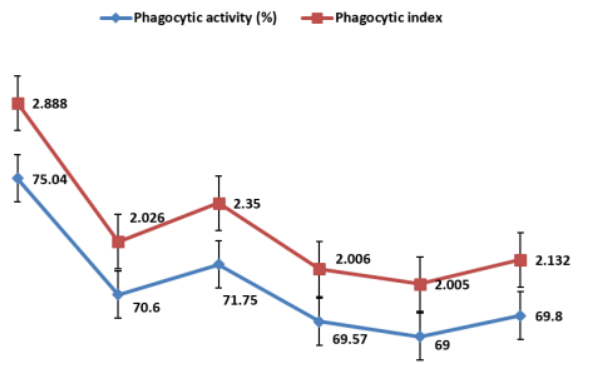

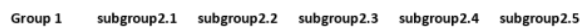

Fig. 1. Phagocytic activity and phagocytic index in apparently healthy and hospitalized dromedary camels. Values were expressed (Mean $\pm \mathrm{SE})$.

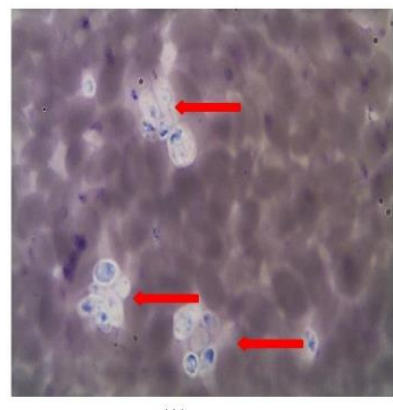

(A)

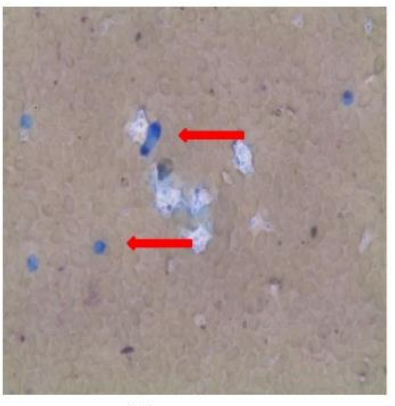

(B)
Fig 2. (A): Blood film showed that engulfed Candida albicans (large numbers) by active neutrophils in good conditioned camel (red arrows). (B): Blood film showed that large numbers of inactive neutrophils in hospitalized camels (red arrows).

\section{Discussion}

In the study reported here, erythrogram and leucogram, serum vitamin $A$ and $E$ concentrations were significantly lower in hospitalized camels compared to healthy ones. Furthermore, trace elements concentrations including copper, zinc and selenium were also lower in hospitalized camels than healthy camels. Of interest, serum vitamin $A$ and $E$ concentrations in addition to serum copper, zinc and selenium concentrations were positively associated with hospitalized camels' immune status. 
Table 6. Univariate analysis of vitamins and trace elements in hospitalized camels based on sex and age.

\begin{tabular}{llccc}
\hline \multicolumn{2}{l}{ Low vitamin A concentrations $<64.3 \mu \mathrm{g} / \mathrm{dl}$} & OR & $95 \%$ CI & P-Value \\
\hline \multirow{2}{*}{ Sex } & Female & $2.1^{*}$ & $1.04-5.2$ & 0.03 \\
& Male & 0.85 & $0.65-3.42$ & 0.6 \\
\multirow{2}{*}{ Age } & $<6$ years & $1.4^{*}$ & $1.02-2.6$ & 0.04 \\
& $>6$ years & 1.2 & $0.82-4.9$ & 0.4 \\
\hline \multirow{2}{*}{ Low vitamin E concentrations $<0.8(100 \mathrm{mg} / \mathrm{ml})$} & OR & $95 \%$ CI & P-Value \\
\hline \multirow{2}{*}{ Sex } & Female & $1.7 *$ & $1.22-3.8$ & 0.04 \\
& Male & 0.63 & $0.56-1.84$ & 0.8 \\
Age & $<6$ years & $1.32 *$ & $1.12-4.2$ & 0.03 \\
& $>6$ years & 0.75 & $0.45-1.75$ & 0.6 \\
\hline
\end{tabular}

Additionally the likelihood of low concentrations of vitamin $\mathrm{A}, \mathrm{E}$, zinc and selenium concentrations were associated with female hospitalized camels and younger ones $<6$ years old during time of admission. $\mathrm{RBCS}, \mathrm{Hb}$ and PCV values were significantly lower in hospitalized camels compared to healthy ones, similar results were reported by previous camel research studies (Gernsten, 2009; Bunn, 2011; DeMoranville and Best, 2013). The lowest values of RBCs, $\mathrm{Hb}$ and PCV were recorded in subgroup 1 and subgroup 3 where copper was deficient between two subgroups. Potential explanations are multifactorial including malnutrition, iron, copper, folate, vitamin B12, vitamin B6 deficiencies (Gernsten, 2009; Bunn, 2011). However, folate, vitamin B6 and B12 concentrations were not measured in this study. Another possible explanation is reduced concentrations of vitamin A and selenium in hospitalized camels (Faye et al., 2009). It was documented that vitamin $\mathrm{A}$ and selenium deficiency was associated with remarkable signs of anemia and reduction of hemoglobin concentrations, PCV and RBCS comparing to apparently healthy camels (El Khouly et al., 2001; Faye et al., 2009). Thereby, it is feasible that reduced concentrations of vitamin A, E, selenium and copper due to the effect of diseases leads to alteration of erythrogram dynamics in camels. The hospitalized camels of this study have shown clinical signs of diarrhea and/or constipation suggesting digestive disorders (Alsaad, 2009). Furthermore, the presence of ticks and pale mucus membrane of hospitalized camels could indicate that increased prevalence of blood parasite in the reared area of camels that in turn could play a role in alteration of erythrogram and immune status of hospitalized camels (Alsaad, 2009).

Interestingly, WBCS were significantly lower in hospitalized camels. Furthermore, we documented neutropenia, lymphopenia, eosinophilia in hospitalized camels. Decreased neutrophil and lymphocytic count in hospitalized camels could be attributed to decreased copper and zinc concentrations which in turn suppress immunomodulation (Niederman et al., 1994; Nockels, 1994; Soetan et al., 2013). However, copper concentrations was within normal range in poor conditioned diseased camels suggesting that copper may not play a role in decreasing WBCS values in hospitalized dromedary camels. It is plausible that parasitic infestation stimulate eosinophils production in hospitalized camels (Padmaja, 2012).

We have shown that hospitalized camels had reduced concentrations of vitamin A compared to healthy ones. The reduced concentrations of vitamin A in hospitalized camels may be attributed to destruction of vitamin A in diet by many factors such as oxygen, heat, light and acids and/or liver diseases (Olson, 1990; Baraka, 2012). Moreover, we did not find association with its low concentrations with camels' phagocytic activity and index indicating that vitamin A may not play a direct role in camel's immune status..

Serum vitamin E concentrations were significantly lower in hospitalized camels than healthy camels. Possible explanations include prolonged storage of animal hay for long time or secondary to decreased supplementation of vitamin $\mathrm{E}$ in camels' ration (Seboussi et al., 2008; Baraka, 2012). In this study, there was a significant medium positive correlation between vitamin $E$ and phagocytic index suggesting its role in stimulation of immune system against infections as anti-oxidant in hospitalized camels. A literature has been reported that vitamin $\mathrm{E}$ scavenges free radicals e.g. peroxyl radicals and converted into tocopherol radicals, while at the level of trace elements, they can act as pro-oxidants and stimulate leukocytes and macrophages during phagocytosis (McDowell et al., 2007).

Serum trace elements concentrations were lower in hospitalized camels than healthy ones except copper where its concentration was not statistically different between both groups of camels. However, another study documented that the decreased concentrations of copper in hospitalized camels could be attributed to feeding on sandy soil and ration rich in molybdenum 
and sulphates that interfere with copper absorption (Amy, 2011). Other factors that could contribute in reduced selenium and zinc concentrations in hospitalized camels include stress factors, unsaturated fatty acids in clover pastures and vitamin E deficiency (Graham, 1991).

Our study was also showed a medium significant association between low copper concentrations and phagocytic activity and index in hospitalized camels. However, selenium was positively correlated with phagocytic index and activity in hospitalized camels, this correlation remain weak in this study. It has been reported that trace elements are essential for immunomodulation through stimulation of phagocytic cells proliferation and migrations (Hefnawy and Tortora, 2010). Additionally a recent literature stated that copper, zinc and selenium supplementation improve phagocytic activity and copper/zincsuperoxide dismutase and ceruloplasmin in animals (Yatoo et al., 2013) suggesting that low concentrations of trace elements may play a role in decreasing resistance of dromedary camels against pathological conditions.

Concentrations of total protein and albumin were decreased in hospitalized camels compared to apparently healthy ones. Potential explanations include digestive disorders such as liver affections and decrease protein levels during blood parasite course (Alsaad, 2009). However, liver biomarkers were not assessed in the present study.

In young and female hospitalized camels, serum vitamin $\mathrm{A}$ and $\mathrm{E}$, zinc and selenium concentrations were more likely to be low compared to male and old age hospitalized ones. We speculate oxidative stress levels were higher in female hospitalized camels and camels with age below than 6 years old that in turn could decrease concentrations of vitamin A, E, zinc and selenium. Similar result was observed in human patients (Brunelli et al., 2014). Reduced selenium concentrations were common in young animals and lead to white muscle disease including degenerative myocarditis and discoloration of skeletal muscle (Faye and Seboussi, 2009). However, oxidative biomarkers were not measured that considered a limitation of this study.

\section{Conclusions}

In conclusion, reduced vitamin $\mathrm{A}$ and $\mathrm{E}$ and other trace elements are frequent in hospitalized dromedary camels during course of diseases. Vitamin E, selenium and zinc concentrations could be used as predictors of health outcomes in hospitalized camels because of their association with phagocytic activity and index allowing hospitalized camels less resistant to the diseases. Low vitamin $\mathrm{A}$ and $\mathrm{E}$ together with decreased zinc and selenium concentrations in female and young age hospitalized camels at time of admission may indicate higher oxidative stress. However, future studies will be required to assess oxidative biomarkers based on different age and sex to monitor diseases progression in hospitalized camels. This study was carried out on small number of hospitalized camels $(n=30)$ at the veterinary hospital which is considered a limitation, but the information from this study could be a predictor of health outcomes in hospitalized dromedary camels.

\section{Acknowledgments}

We want to thank all veterinarian and technical staff for their support and help to carry out this study.

\section{Conflict of interest}

The authors declare that there is no conflict of interest.

\section{References}

Abe, A., Yamashita, S. and Noma, A. 1989. Clinical Chemistry. 35, 552-554.

Alsaad, K. 2009. Clinical, Hematological and Biochemical Studies of Anaplasmosis in Arabian One-Humped Camels (Camelus dromedaries). J. Anim. Vet. Adv. 8, 1794-1797.

Amy, P. 2011. Pasture-Applied Copper Study in Coos County, Oregon. Available at: http://extension.oregonstate.edu/coos/

Baraka, T. A. 2012. Clinical evaluation of Vitamin A, B-Carotene, Vitamin E and cortisol levels in Health and Selected Diseases in Camels (Camelus dromedarius) in Egypt. J. Am. Sci. 8(1s), 106-111.

Bennett, P.N. and Brown, M.J. 2003. Clinical Pharmacology. Churchill Livingstone, pp; 735-774.

Bhaskaram, P. 2002. Micronutrient malnutrition, infection and immunity. Nutr. Rev. 60, S40-S45.

Brunelli, E., Domanico, F., La Russa, D. and Pellegrino, D. 2014. Sex differences in oxidative stress biomarkers. Curr. Drug Targets 15, 811-815.

Bunn, H.F. 2011. Approach to the anaemias. In: Goldman, L. and Schaffer, A.I. eds. Cecil Medicine. $24^{\text {th }}$ ed. Philadelphia, Pa: Saunders Elsevier, pp: 161 .

Coles, H.E. 1986. Veterinary clinical pathology $4^{\text {th }}$ Ed., Philadelphia, London, Tokyo, Sydney, Hong Kong.

Crabb, D., Manwaring, J. and Connor, T. 1990. Feeding Standards for Australian Livestock. J. Dairy. Sci. 70, 2732-2743.

DeMoranville, V.E. and Best, M.A. 2013. Haematocrit. Encyclopedia of Surgery. A guide for patients and caregivers. Available at: enwikipedia.org /wiki/haematology.

Doumas, B.T. 1975. Colorimetric determination of total protein. Clin. Chem. 21, 1159-1166.

Duester, G. 2008. Retinoic acid synthesis and signaling during early organogenesis. Cell 134, 921-931.

El Khouly, A.A., Abbas, T.A. and Moustafa, T. 2001. Myocardial dystrophy in camel calves in the United Arab Emirates (field cases). Emirates J. Agric. Sci. $13,11-17$. 
Faye, B., Bengoumi, M., Cleradin, A., Tabarani, A. and Chilliard, Y. 2001. Body condition score in dromedary camel: A tool for management of reproduction. Emirates J. Food Agric. 1-6.

Faye, B., Seboussi, R. and Alhadrami, G. 2009. Metaanalysis of the interactions between selenium status and haematological, biochemical and mineral parameters in camel blood. Trends Comp. Biochem. Physiol. 14, 25-34.

Faye, B. and Seboussi, R. 2009. Selenium in camel-A review. Nutrients 1(1), 30-49.

Gernsten, T. 2009. Medline plus Medical Encyclopedia: RBC Indices. Available at: en.wikipedia.org/wiki/red_blood_cell_indices.

Graham, T.W. 1991. Trace element deficiencies in cattle. Vet. Clin. North Am. Food Anim. Pract. 7, 153-215.

Hambidge, M. 2003. Biomarkers of trace mineral intake and status. J. Nutr. 133, 948S-955S.

Hefnawy, A.E.G. and Tórtora-Pérez, J.L. 2010. The importance of selenium and the effects of its deficiency in animal health. Small Rumin. Res. 89, 185-192.

Johnsen, O. and Eliasson, R. 1987. Evaluation of commercially available kit for the colorimetric determination of zinc in human seminal plasma. Int. J. Androl. 10(2), 435- 440.

McDowell, L.R., Wilkinson, N., Madison, R. and Felix, T. 2007. Vitamins and minerals functioning as antioxidants with supplementation considerations. In Florida Ruminant Nutrition Symposium; Best Western Gateway Grand: Gainesville, FL, USA, pp: 30-31.

Mehrzad, J., Maleki, M., Raji, A. and Ramzi, G. 2014. An ultrastructural investigation of the blood neutrophils in camel (camelus dromedarius). Comp. Clin. Pathol. 23(4), 885-892.

Nayyar, S. and Jindal, R. 2010. Essentiality of antioxidant vitamins for ruminants in relation to stress and reproduction. Iranian J. Vet. Res. 11, 1-9.

Niederman, C.N., Blodgett, D., Eversole, D., Schurig, G.G. and Thatcher, C.D. 1994. Effect of copper and iron on neutrophil function and humoral immunity of gestating beef cattle. J. Am. Vet. Med. Assoc. 204, 1796-1800.

Nockels, C.F. 1994. Micornutrients and the immune response. In: Montana Nutrition Conference Proceedings. Bozeman, Montana pp: 3.1.

Olson, R.E. 1990. Pantothenic acid. In: Nutrition Reviews, Present Knowledge in Nutrition, (R.E.
Olson, Ed.), Nutrition Foundation, Washington, D.C., pp: 208.

Padmaja, K. 2012. Hemato-biocemical studied on camels infested with trypanosomiasis. Vet. World 5, 356- 358

Pourjafar, M., Khalil, B., Saeed, S., Aliasghar, C., Azin, S. and Mojtaba, N. 2014. Correlations between Serum Trace Elements (Selenium, Copper and Zinc) and Antioxidant Vitamins (Vitamin A, E and C) in Clinically Healthy Dromedary Camels. J. Fac. Vet. Med. Istanbul Univ. 40(1), 7-13.

Robert, G.M. 1964. Methods for the determination of vitamin $\mathrm{E}$ (total tocopherols) in serum. Clin. Chem. 10(12), 1078-1086.

Roitt, I.M., Brostoff, J. and Male, D.K. 1996. Immunology, $4^{\text {th }}$ ed. Gower Medical Publishing $1^{\text {st }}$, London.

Schalm, O.W., Jain, N.C. and Carroll, E.J. 1975. Veterinary hematology. $3^{\text {rd }}$ Ed. Philadelphia, Lea and Fibiger.

Seboussi, R., Faye, B., Alhadrami, G., Askar, M., Ibrahim, W., Hassan, K. and Mahjoub, B. 2008. Effect of different selenium supplementation levels on selenium status in camel. Biol. Trace. Elem. Res. 123(1-3), 124-38.

Soetan, K.O., Akinrinde, A.S. and Ajibade, T.O. 2013. Preliminary studies on the haematological parameters of cockerels fed raw and processed guinea corn (Sorghum bicolor). Proceedings of $38^{\text {th }}$ Annual Conference of Nigerian Society for Animal Production, pp: 49-52.

Suzuki, J. and Katoh, N. 1990. A simple and cheap method for measuring serum vitamin $A$ in cattle using only a spectrophotometer. Japanese J. Vet. Sci. (52), 1281-1283.

Tietz, N.W. 1999. Text book of clinical chemistry, $3^{\text {rd }}$ edition. Burtis CA, Ashwood ER. WB Saunders Co.

Tsoumbaris, P. 1990. Heavy metals Determination in food stuff. PhD Thesis, Thessalonica, Greece.

Underwood, B.A. and Auther, P. 1996. The contribution of vitamin A to public health. FASEB J. 10, 1040-1048.

Wilkinson, P.C. 1981. Techniques in clinical immunology. $2^{\text {nd }} \mathrm{Ed}$.

Yatoo, M.I., Saxena, A., Deepa, P.M., Habeab, B.P., Devi, S., Jatav, R.S. and Dimri, U. 2013. Role of trace elements in animals: a review. Vet. World 6(12), 963-967.

Young, D.S. 2001. Effects of disease on clinical lab. Tests, $4^{\text {th }}$ Ed. AACC, Washington DC, USA. 